\title{
Listening to the hidden sounds in the forest
}

\author{
A.J. Najar-Rodriguez, S. Sapkota and S. Burgess \\ Plant \& Food Research Limited, , Private Bag 11600, Palmerston North 4442, New Zealand \\ Corresponding author: adriana.najar-rodriguez@plantandfood.co.nz
}

Many bark beetles (Coleoptera: Curculionidae: Scolytinae) exhibit a wide array of acoustic abilities including sounds used in mate attraction, territoriality and defence. In New Zealand, the golden-haired bark beetle Hylurgus ligniperda and the black pine bark beetle Hylastes ater are two species of forest insects which may be found on export logs. Acoustic signals have been shown to discourage a related bark beetle, the western pine beetle Dendroctonus, from entering into pine logs and to disrupt mating and tunnelling. These recent studies combined with observations of $H$. ligniperda and $H$. ater helped to establish the concept that acoustic disruption could be used as part of a wider systems approach to deter these beetle species near saw mills, skid sites and ports. If proven effective, this technique would add value to New Zealand log exports and decrease the reliance on toxic fumigants as the primary control measure. This study shows some of the functions and physical characteristics of the acoustic signals produced by $H$. ligniperda and $H$. ater.

\section{Brown marmorated stink bug - current or planned research to prevent its establishment and to reduce its impact in New Zealand}

\author{
D.A.J. Teulon ${ }^{1}$, T.C. Leskey ${ }^{2}$ and C. Duthie ${ }^{3}$
}

${ }^{1}$ Better Border Biosecurity, C/- Plant \& Food Research, Private Bag 4704, Christchurch 8140, New Zealand ${ }^{2}$ USDA-ARS, Appalachian Fruit Research Station, Kearneysville WV, 25430-2771 USA ${ }^{3}$ Ministry for Primary Industries, 25 The Terrace, PO Box 2526, Wellington, New Zealand Corresponding author: David.Teulon@plantandfood.co.nz

Brown marmorated stink bug (BMSB; Halyomorpha halys) originates from Asia and is currently spreading rapidly throughout the world but is not yet recorded in the southern hemisphere. BMSB has a wide host range and in some regions it has become a major nuisance and a plant pest of significant economic importance for some fruit, vegetable and ornamental crops. Since 2014, raised awareness of BMSB's potential destructive impact in New Zealand and increasing border interceptions have led to a greater focus on research required to prevent its establishment and to reduce its potential impact. Key contributions in developing BMSB research priorities and activities for New Zealand have come from several sources including an MPI Risk Assessment (2012), a keynote presentation at the 2014 B3 Conference, several Ministry for Primary Industry/Department of Conservation/industry/researcher workshops, methodical engagement of international BMSB experts, and a cross-MPI preparedness project. Research has been initiated or is planned across the biosecurity spectrum to answer key questions about risk assessment, pathway risk management, diagnostics, surveillance and eradication. 